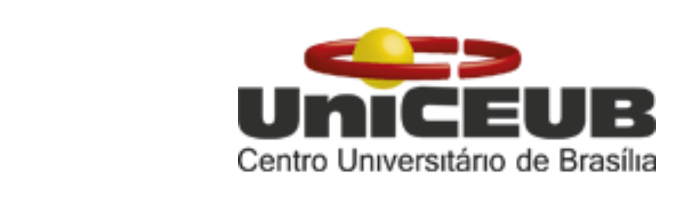

CENTRO UNIVERSITÁRIO DE BRASÍLIA - UnICEUB

PROGRAMA DE INICIAÇÃO CIENTÍFICA

ANA CAROLINA LARAIA

KÁLYDA SANTANA

AVALIAÇÃO DA RESPOSTA DE ANTICORPOS VACINAIS EM ANIMAIS VACINADOS CONTRA LEISHMANIOSE VISCERAL CANINA

BRASÍLIA 


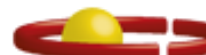 \\ Unce=UB \\ Centro Unıversıtárıo de Brasílıa
}

\author{
ANA CAROLINA LARAIA
}

KÁLYDA SANTANA

\section{AVALIAÇÃO DA RESPOSTA DE ANTICORPOS VACINAIS EM ANIMAIS VACINADOS CONTRA LEISHMANIOSE VISCERAL CANINA}

\author{
Relatório final de pesquisa de Iniciação Científica \\ apresentado à Assessoria de Pós-Graduação e Pesquisa. \\ Orientação: Lucas Edel Donato
}

BRASÍLIA 


\section{AGRADECIMENTOS}

Essa pesquisa foi um divisor de águas em nossa trajetória na universidade, apendemos muito, e estamos muito felizes por termos um espaço dedicado há agradecer a cada um que esteve ao nosso lado nesse percurso.

Primeiramente, agradecemos ao nosso professor e orientador Lucas, o qual aprendemos a admirar e respeitar por todo seu empenho em conduzir firme nossa pesquisa, sempre com compreensão e acreditando em nossa capacidade. Somos gratas a amizade despertada durante esta jornada, esse trabalho em grande parte também é mérito teu.

Aos nossos pais, avós e irmãs, agradecemos imensamente o apoio incondicional, por todas as atitudes que tornaram possível a construção dessa pesquisa, não há palavras que possam expressar a gratidão que sentimos por todo apoio e incentivo que recebemos.

Gostaríamos de agradecer a todo batalhão do Sexto Comando Aéreo da Aeronáutica de Brasília, que contribuíram de alguma forma ao nosso estudo, em especial a todos os cães que participaram da amostra, sem eles nada disso seria possível. Os animais são em nosso maior incentivo para ingressão nesse estudo e seremos eternamente gratas pela vida de cada um desses guerreiros, que muito além da pesquisa, nos ajudam todos os dias servindo ao nosso país com todo empenho e amor possível.

Agradecemos a todos os funcionários que tivemos contato no Instituto Carlos Chagas, da Fundação Oswaldo Cruz, em Curitiba/PR, fomos recebidas com muito carinho, e teremos sempre na memória os aprendizados e dias incríveis que vivemos.

Agradecemos também a Diretoria de Vigilância Ambiental em Saúde (DIVAL), pelo auxilio na execução dos exames laboratoriais.

E também não podemos deixar de agradecer a instituição pela oportunidade ímpar, por acreditar não só na nossa pesquisa, mas por incentivar o despertar e trazer aos alunos a visão de que pesquisas são necessárias na formação de bons profissionais. Salientamos o apoio incondicional prestado, a forma interessada e pertinente como todos os funcionários na Assessoria de Pesquisa e Extensão prestaram a nós, vocês são profissionais incríveis.

E a todos que não foram citados, mas ajudaram de forma direta ou indireta para esse estudo, nossos mais sinceros agradecimentos. 


\section{RESUMO}

Esta pesquisa discorre sobre as questões que buscam responder: Qual a resposta de anticorpos vacinais em animais vacinados contra leishmaniose visceral canina? Tendo em vista a necessidade de testes sorológicos que não produzam resultados positivos influenciados pela resposta humoral vacinal. O presente estudo avaliou a soroconversão de cães vacinados com a vacina LeishTec por meio dos testes imunocromatográfico DPP-LVC e Alere- LVC e também utilizando da técnica ELISA como teste confirmatório para estes resultados. Como alternativa auxiliar e para melhor acurácia dos resultados todas as amostras foram testadas através da técnica de PCR no Instituto Carlos Chagas - FioCruz Paraná, na cidade de Curitiba/PR. Os testes DPP-LVC e Alere-LVC apresentaram tanto no tempo 0, quanto no tempo 1 , resultados positivos e negativos. Todas as amostras apresentaram teste negativo no exame confirmatório ELISA. As amostras examinadas pela técnica PCR também apresentaram em sua totalidade o resultado negativo. Os resultados dessa pesquisa evidenciam que o protocolo adotado pelo Ministério da Saúde é seguro na detecção de animais infectados com Leishmaniose, visto que as amostras positivas para os testes de triagem (DPP) são testadas pelo teste confirmatório ELISA, proporcionando um método capaz de separar os animais realmente positivos daqueles imunizados. Entretanto a análise documental mostrou, que há indícios da soroconversão de animais testados pelo DPP, fato que deve ser confirmado por estudos mais abrangentes.

Palavras-Chave: Leishmania. Soroconversão. DPP-LVC. 


\section{SUMÁRIO}

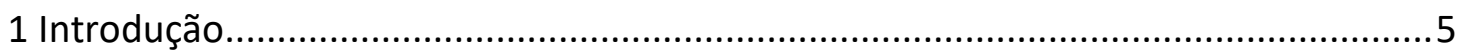

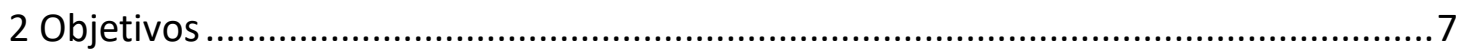

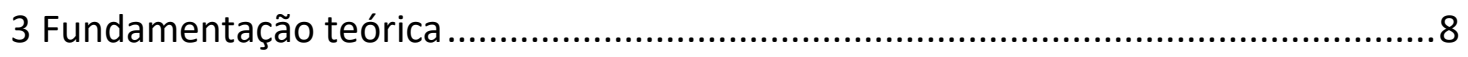

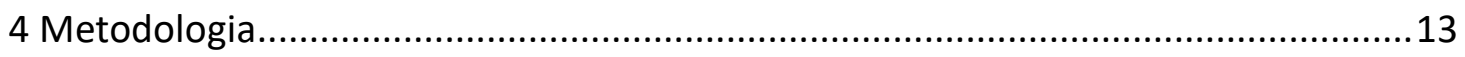

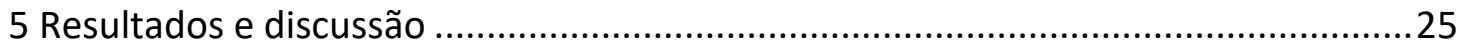

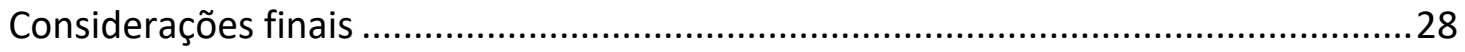

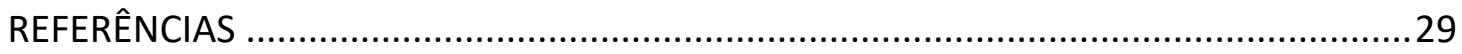




\section{Introdução}

A presente pesquisa está inserida nos estudos relacionados a leishmaniose visceral (LV), que é uma doença que se caracteriza como zoonose e que acomete diversas espécies de mamíferos silvestres e domésticos, tendo como manifestações clínicas de curso crônico e com diversos sinais patológicos. Os cães são considerados o principal reservatório da infecção por Leishmania infantum canina e humana (BANETH, G. SOLANO-GALLEGO 2015). A infecção é transmitida pela picada da fêmea do flebotomíneo, do gênero Lutzomyia (BANETH, G. SOLANO-GALLEGO, 2015). Atualmente, a leishmaniose é considerada uma das seis doenças infecciosas mais relevantes no mundo (FERNANDES et al., 2019).

Este trabalho discorre sobre as questões que norteam: Qual a resposta de anticorpos vacinais em animais vacinados contra leishmaniose visceral canina? Atualmente no país há o registro apenas de um imunobiológico para prevenção da leishmaniose visceral canina (LVC), a vacina Leish-Tec ${ }^{\circledR}$ (CEVA Saúde Animal ${ }^{\circledR}$, São Paulo, Brasil). Este insumo possui uma formulação contendo a proteína recombinante A2 de Leishmania donovani (REGINA-SILVA et al., 2016). As respostas imunitárias produzidas em cães, forneceram indícios de respostas protetoras contra Leishmaniose Visceral Canina (LVC), entretanto o Ministério da Saúde (MS) não recomenda a vacina como única forma de controle da leishmaniose, por não haver evidência científica que o seu uso em massa seja capaz de reduzir a infecção em cães e consequentemente a infecção em humanos. Ademais Campos et al (2017) relata a possível influência da resposta humoral nos testes sorológicos utilizados pelo Programa de Vigilância e Controle da Leishmaniose Visceral do Ministério da Saúde, impedindo a distinção entre animais vacinados dos realmente infectados. Segundo Fernandes (2019) os diagnósticos de cães infectados é um desafio para o controle efetivo da doença. Atualmente, testes sorológicos imunoenzimáticos (ELISA) e imunocromatográficos (Dual Path Platform, BioManguinhos) são recomendados para o diagnóstico de Leishmania spp. em cães do Brasil (BRASIL, 2011). No entanto, autores como Trocanrelli (2009) e Grimaldi (2012) discorrem sobre a questão de testes sorológicos apresentarem algumas limitações como por exemplo a baixa sensibilidade no diagnóstico em cães sem sinais clínicos e também reações cruzadas com outros tripanossomatídeos. 
Tendo em vista a necessidade de testes sorológicos que não produzam resultados positivos influenciados pela resposta humoral vacinal. O presente estudo avaliou a soroconversão de cães vacinados com a vacina LeishTec por meio dos testes por meio dos testes imunocromatográfico DPP-LVC e Alere- LVC o estudo foi realizado no canil do Sexto Comando Aéreo Regional (VI COMAR), localizado na região administrativa do Lago Sul área endêmica para LVC. 


\section{Objetivos}

Avaliar a resposta de anticorpos vacinais em animais vacinados contra leishmaniose visceral canina.

\section{1 Objetivos Específicos}

- Avaliar a soroconversão em cães vacinados, por meio do teste imunocromatográfico (DPP- LVC);

- Avaliar a soroconversão em cães vacinados, por meio do teste imunocromatográfico (Alere - LVC).

- $\quad$ Avaliar a infecção de cães vacinados contra LVC, através do teste molecular qPCR. 


\section{Fundamentação teórica}

Segundo Oliveira (2015), a leishmaniose visceral (LV) é uma doença de grande relevância para saúde pública por se tratar de uma zoonose de difícil controle e que ocorre em diferentes países da América Latina, África, Ásia e Europa. No Brasil, a LV é causada pelo protozoário Leishmania infantum e o Lutzomyia longipalpis é o principal vetor biológico envolvido na transmissão desse parasito.

As leishmanioses têm sido descritas em vários animais domésticos e selvagens, incluindo carnívoros, marsupiais, roedores, equídeos e primatas (ASHFORD, 1996; COURA, 2009; COURA, 2013; BENASSI et al., 2017). Nas áreas urbanas, o cão (Canis familiaris) é o principal reservatório de $L$. infantum e a fonte de infecção do vetor (OLIVEIRA, 2015; SILVA et al., 2015) devido à sua alta susceptibilidade a infecções e maior proximidade ao homem, além de seu elevado parasitismo cutâneo, que contribui para a manutenção e ampliação do ciclo de transmissão em ambientes domésticos (SILVA et al., 2015)

Sobre o ciclo da infecção que envolve um vetor e um hospedeiro vertebrado, Baneth, G. Solano-Gallego (2015), explica que no hospedeiro vertebrado, a Leishmania é encontra-se nas células de defesa do organismo, os macrófagos, estando na sua forma não flagelada, o amastigota, que tem o formato ovoide. Essa forma do protozoário se multiplica por divisão binária, rompe a membrana célula causando a lise do macrófago infectando outras células. As proposições de Moraes (2013) e Sundar (2015), reafirmam que as fêmeas do Lutzomya se alimentam de sangue, dessa forma ela ingere amastigotas no momento do repasto sanguíneo. No entendimento de Baneth, G. Solano-Gallego (2015) no intestino do flebotomíneo, os amastigotas são liberados das células hospedeiras, sofrendo várias alterações morfológicas e transformam-se em promastigota flagelada, um organismo extracelular.

Alguns autores relatam ao longo dos últimos anos como é explicada a patogênese da infecção por Leishmania, através da picada do flebotomíneo, a forma promastigota do protozoário é transferida com a saliva para a pele do hospedeiro vertebrado. Logo após, os promastigotas são fagocitadas por macrófagos e multiplicam-se na forma de amastigotas dentro das células. Quando o macrófago está repleto de amastigotas, sofre a lise através da ruptura, e libera as amastigotas, que por sua vez, penetram em outras células do hospedeiro e disseminam-se a partir do local de picada. Dessa forma o protozoário percorre todo corpo do hospedeiro, porém se dirige mais especificamente para órgãos hemolinfáticos, tais como linfonodos, baço, medula óssea e fígado, bem como para áreas dérmicas remotas, 
estabelecendo infecção sistêmica (TAYLOR, 2010; COURA 2013; BANETH, G. SOLANOGALLEGO, 2015; SUNDAR, 2015).

Alguns autores como Taylor (2010) e Ibraim (2012) explicam sobre a resposta imune inata ou inespecífica, que no animal é a primeira linha de defesa que os parasitos Leishmania defrontam quando entram em hospedeiro suscetível. Assim como Baneth, G. Solano-Gallego (2015) o autor Ibraim (2012), explica que os amastigotas possuem uma capacidade de sobreviver à resposta imune inata e replicar-se dentro de fagolisossomos de macrófagos, pois produzem compostos como os lipofosfoglicanos, que inibem a maturação dos fagossomas. Taylor (2010) e Baneth, G. Solano-Gallego (2015) ressaltam que as respostas imunes específicas têm importante papel na suscetibilidade à infecção. Os dois autores explicam que animais que tipicamente desenvolvem uma resposta de células T auxiliares tipo 2 ou simplesmente Th2, desenvolveram à infecção. Já a resposta imune Th2 de cães secreta citocinas específicas, como IL-4 e IL-10 produzindo uma resposta humoral significativa sendo menos efetiva ao parasito. Baneth, G. Solano-Gallego 2015, resume a resposta imune explicando que alguns animais respondem com um conjunto de citocinas diferentes, incluindo a interferon gama (IFN- $\gamma$ ) e IL-12, citocinas típicas de uma resposta Th tipo 1 ou Th1, esses animais são considerados resistentes à infecção pois a IFN- $\gamma$ secretada pelas células T ativa os macrófagos que causam a eliminação dos parasitos. Esse conceito geral - em que um tipo de resposta de célula Th produz resistência ou cura, enquanto o segundo tipo produz suscetibilidade e exacerbação da doença -, irá ser aplicado a infecções por outros patógenos em muitos hospedeiros.

Após entender as colocações de Baneth, G. Solano-Gallego (2015), sobre os tipos de respostas ao patógeno da Leishmania, é mais fácil a compreensão sobre as preposições de Moreira (2016) e Oliveira (2015), que relatam os sinais clínicos da LVC como amplos e variáveis, incluindo sinais neurológicos como convulsões, além de linfadenomegalia local ou generalizada, perda de peso, caquexia, falta de apetite, letargia, esplenomegalia, poliúria, polidipsia, lesões oculares, vômitos e diarreia, alterações visuais, sinais de paralisia do nervo craniano, tremor intencional, vocalização, hemiparesia, paraparesia, paraplegia e tetraplegia. Oliveira (2015), ainda descreve que a grande maioria dos cães diagnosticados com LVC podem apresentar lesões oculares, incluindo conjuntivite, blefaríte, ceratoconjuntive e uveíte. Moreira (2016), complementa Oliveira (2015) ressaltando que as lesões dermatológicas causadas pela infecção da LVC podem variar entre a sua proliferação, mas raramente são 
pruriginosas. O comprometimento visceral apresenta os sinais clínicos mais comuns da LVC que são a perda de peso e a atrofia muscular.

Segundo Fernandes (2019) os diagnósticos de cães infectados é um desafio para o controle efetivo da doença. Atualmente, testes sorológicos imunoenzimáticos (ELISA) e imunocromatográficos (Dual Path Platform, Bio-Manguinhos) são recomendados para o diagnóstico de Leishmania spp. Em cães do Brasil (BRASIL, 2011). No entanto, autores como Trocanrelli (2009) e Grimaldi (2012) discorrem sobre a questão de testes sorológicos apresentarem algumas limitações como por exemplo a baixa sensibilidade no diagnóstico em cães sem sinais clínicos e também reações cruzadas com outros tripanossomatídeos.

De acordo com o que foi citado por Campos 2017, O MS do Brasil recomenda que os testes sorológicos - DPP ${ }^{\circledR}$ (Dual Path Platform) (DPP CVL), seja realizado para a triagem de cães, como regulamenta a NOTA TÉCNICA N ${ }^{\circ} 01 / 2011$, e que animais com resultados reagentes em ambos os testes precisam ser eutanasiados como uma alternativa ao tratamento da doença e uma medida de controle. A eutanásia dos cães infectados, gera um grande apelo social, não parecendo ser eficaz, considerando que a LVC se expandiu para áreas não endêmicas.

Segundo Costa 2014, o MS recomenda duas técnicas sorológicas para avaliação sorológica em cães, sendo a triagem realizada com o teste rápido Dual Path Platform (TR$D P^{\oplus}$ ) e o teste confirmatório, o ensaio imunoenzimático (ELISA - Enzyme Linked Immunosorbent Assay). Complementarmente Campos 2017, relata que estudos atuais demonstraram que a sensibilidade e especificidade da técnica TR-DPP ${ }^{\circledR}$ pode atingir $87,5 \%$ e que melhorou significativamente o diagnóstico de LVC desde que o novo protocolo (DPP LVC e EIE) foi implementado.

Costa 2014, explica que o teste rápido Dual Path Platform (TR-DPP ${ }^{\circledR}$ ), que tem sua patente confirmada pela Chembio Diagnostic, e foi desenvolvido pelo Instituto Biomanguinhos/Fiocruz, é um ensaio imunocromatográfico que emprega de um dos lado, a combinação de um corante insolúvel (partículas de ouro coloidal) e de uma proteína A conjugada, enquanto que do outro lado, há presença de antígenos 36 recombinantes k28 (fusão do rk39, rk26 e rk9), específicos do complexo Leishmania donovani, ligados a uma membrana. Se anticorpos anti-Leishmania forem detectados na amostra que foi submetida ao teste, as substâncias impregnadas irão reagir com os antígenos recombinantes, trazendo como resultante o laudo positivo através da reação que pode ser identificada pela presença 
de uma linha de tom rosa. Figueiredo (2018), relata que o teste Alere também demonstra alta sensibilidade utilizando o mesmo antígeno recombinante rK28. Cabe destacar que se torna imprescindível que o teste de triagem apresente alta sensibilidade quando utilizado nos programas de saúde pública.

No relato de Campos 2017, existiam no Brasil, duas vacinas anti-LVC foram desenvolvidas e lançadas comercialmente: Leishmune ${ }^{\circledR}$ (Zoetis $^{\circledR}$, New Jersey, EUA) e LeishTec $^{\circledR}$ (Hertape Calier Saúde Animal ${ }^{\circledR}$, Minas Gerais, Brasil). Porém, a Leishmune ${ }^{\circledR}$ teve sua comercialização temporariamente suspensa pelo Ministério da Agricultura, Pecuária e Abastecimento (MAPA) no ano de 2016 pois não cumpriu completamente os pré-requisitos da fase III do ensaio de avaliação da eficácia da vacina (MAPA, NOTA TÉCNICA 038/2014). Portanto, a Leish-Tec ${ }^{\circledR}$ (Hertape Calier Saúde Animal ${ }^{\circledR}$, Minas Gerais, Brasil) é atualmente a única vacina anti-LVC comercializada e disponível no Brasil. Apesar da vacina ter sua comercialização aprovada pelo MAPA, o MS não recomenda seu uso para fins de saúde pública, pois não há evidência científica de que a vacina seja capaz de controlar a infecção nos cães quando utilizada para fins de saúde pública, considerando que os principais testes de triagem e confirmação (DPP LVC e EIE) são sorológicos, e isso possibilita uma resposta imune humoral provocada pela vacina interferir no diagnóstico, impossibilitando a distinção de animais vacinados de animais infectados nos testes sorológicos recomendados pelo MS. Como alternativa aos testes indiretos, o autor Gramiccia (2011) ressalta que os métodos moleculares têm um papel importante para a confirmação e identificação de Leishmania spp. e, portanto para a deteç̧ão de portadores.

Segundo Coelho et al. (2003), a vacina LeishTec ${ }^{\circledR}$ é formulada sobre a base da proteína recombinante $\mathrm{A} 2$ de $L$. (L.) donovani, produzida em bactérias gram positivas Escherichia coli, sob a forma de antígeno recombinante e saponina como adjuvante. Esta proteína é expressa em formas amastigotas do protozoário de algumas Leishmanias, como L. (L.) donovani, L. (L.) infantum, L. (L.) amazonensis e L. (L.) mexicana. Vários ensaios pré-clínicos em camundongos forneceram evidências das respostas protetoras induzidas pela vacinação com o antígeno $A 2$ de amastigota, em combinação com diferentes adjuvantes, contra a leishmaniose visceral (Coelho et al., 2003; Ghosh et al., 2001; Ghosh et al., 2002; Zanin et al., 2007; Resende et al., 2008; Mizbani et al., 2009). Um estudo conduzido por Fernandes et al. (2008), com cães da raça beagles, demonstrou que a vacina Leish-Tec ${ }^{\circledR}$ pode induzir no sistema imune uma proteção contra a infecção por alta dose intravenosa de L. (L.) infantum induzida. A Leish-Tec ${ }^{\circledR}$ 
é atualmente a única vacina anti-LVC licenciada no Brasil, e seu uso é restrito é individual e restrito aos médicos veterinários.

Diversos métodos podem ser utilizados para a obtenção de um diagnóstico para LVC, mas é sempre de fundamental importância fazer uma associação das informações clínicas e epidemiológicas aos resultados de laboratório. O diagnóstico confirmatório de qualquer processo infeccioso parasitário é indicado a realizar um teste que encontre o parasito nos tecidos ou fluidos biológicos dos hospedeiros. Nesse sentido é recomendado a confirmação do diagnóstico por método parasitológico antes que seja dado início ao tratamento (COSTA, 2014).

$\mathrm{Na}$ literatura diversos autores apontam que as principais desvantagens dos testes sorológicos seriam as possíveis falhas na detecção de cães infectados antes da soroconversão, a impossibilidade de diferenciar animais infectados e resistentes, e a suscetibilidade às reações cruzadas com outras doenças que atingem os cães com por exemplo a neosporose, babesiose, erliquiose e tripanosomíase trazendo como risco de eutanasiar um cão falsopositivo (HARRUS et al., 2002; LEAL. 2009; LOPES et al., 2011; SILVA et al., 2011; LUCIANO et al., 2016).

O Brasil está na lista dos seis países mais afetados pela LV e, segundo o MS dados mostram que mais de 3 mil pessoas são infectadas pelos parasitos todos os anos no país devido a essa zoonose. Os cães são considerados o maior reservatório urbano da LV, mas a responsabilidade por esses números e da população e serviços públicos de saúde, por isso é de suma importância a prevenção seja realizada. A população deve agir para evitar que as condições favoráveis à presença do vetor em suas casas e entorno seja mantida. Já os serviços públicos de saúde, têm o dever de garantir a assistência necessária aos acometidos, assim como orientar a população sobre importância dessa zoonose com práticas de educação em saúde. 


\section{Metodologia}

\subsection{Desenho do estudo}

Este estudo foi realizado sob aprovação da comissão de ética no uso de animais do UniCEUB (CEUA/UniCEUB), registrada com o n॰ PIC(A) 008/2018.

Trata-se de um estudo de coorte no qual 9 cães do canil da Força Aérea Brasileira (VI Comando Aéreo Regional - COMAR), situado nas coordenadas $15^{\circ} 51^{\prime} 28^{\prime \prime} \mathrm{S} 47^{\circ} 54^{\prime} 11^{\prime \prime} \mathrm{W}$, foram submetidos à coleta de amostras biológicas para o diagnóstico em diferentes períodos após a vacinação contra LVC para avaliação dos padrões imunológicos.

\subsection{População do estudo}

Nove cães do canil da IV COMAR foram imunizados com uma dose da vacina LeishTec $^{\circledR}$ (CEVA Saúde Animal). O protocolo de imunização informado na bula do fabricante foi seguida, em que recomenda 1 dose da vacina com intervalo de 1 ano para animais já vacinados e 3 doses em um intervalo de 21 dias para animais primovacinados. Entretanto, todos os animais já haviam sido vacinados a mais de 1 ano, sendo realizado apenas 1 dose da vacina. Conforme bula e Instrução Normativa no31/2007 (BRASIL, 2007) do Ministério da Saúde e Ministério da Agricultura, Pecuária e Abastecimento somente os animais que apresentaram resultado negativos em 1 dos testes sorológicos de triagem e confirmatório puderam ser imunizados e encoleirados.

Critérios de inclusão: Cães sadios de ambos os sexos com idade superior a quatro meses com testes não reagentes e qPCR negativo.

Critério de exclusão: Fêmeas gestantes, cães imunocomprometidos por medicamento ou doença de base, cães positivos para leishmaniose, cães com amostras biológicas insuficientes para as análises.

Dessa forma, foram selecionados 9 animais para a coleta de amostras, sendo eles 4 fêmeas e 5 machos, um deles com 1 ano de idade, sete com 2 anos de idade e um com 7 anos de idade (ANEXO, 1).

Foi feito o acompanhamento aproximadamente durante o período de 113 dias e realizado a com coleta de amostras em dois momentos: 
-Tempo 0 (11/03/2019): Exames clínicos, coleta das amostras (sangue venoso e medula óssea), para realizar exame sorológico e molecular e vacinação e encoleiramento dos negativos

-Tempo 1 (02/07/2019): coleta das amostras (sangue venoso e medula óssea), para realizar exame sorológico e molecular. Após coleta, as amostras foram encaminhadas ao Instituto Carlos Chagas - Fundação Osvaldo Cruz (IOC-Fiocruz) para a realização do exame molecular qPCR.

\subsection{Coleta de material}

A coleta de dados foi realizada pelas alunas e professor do presente estudo, com a ajuda da médica veterinária da IV COMAR. O local possui infraestrutura clínica para a realização das coletas. Foram utilizados EPI's como jaleco, calça, sapatos fechados e luvas para evitar acidentes.

Figura 1 - Coleta de medula óssea

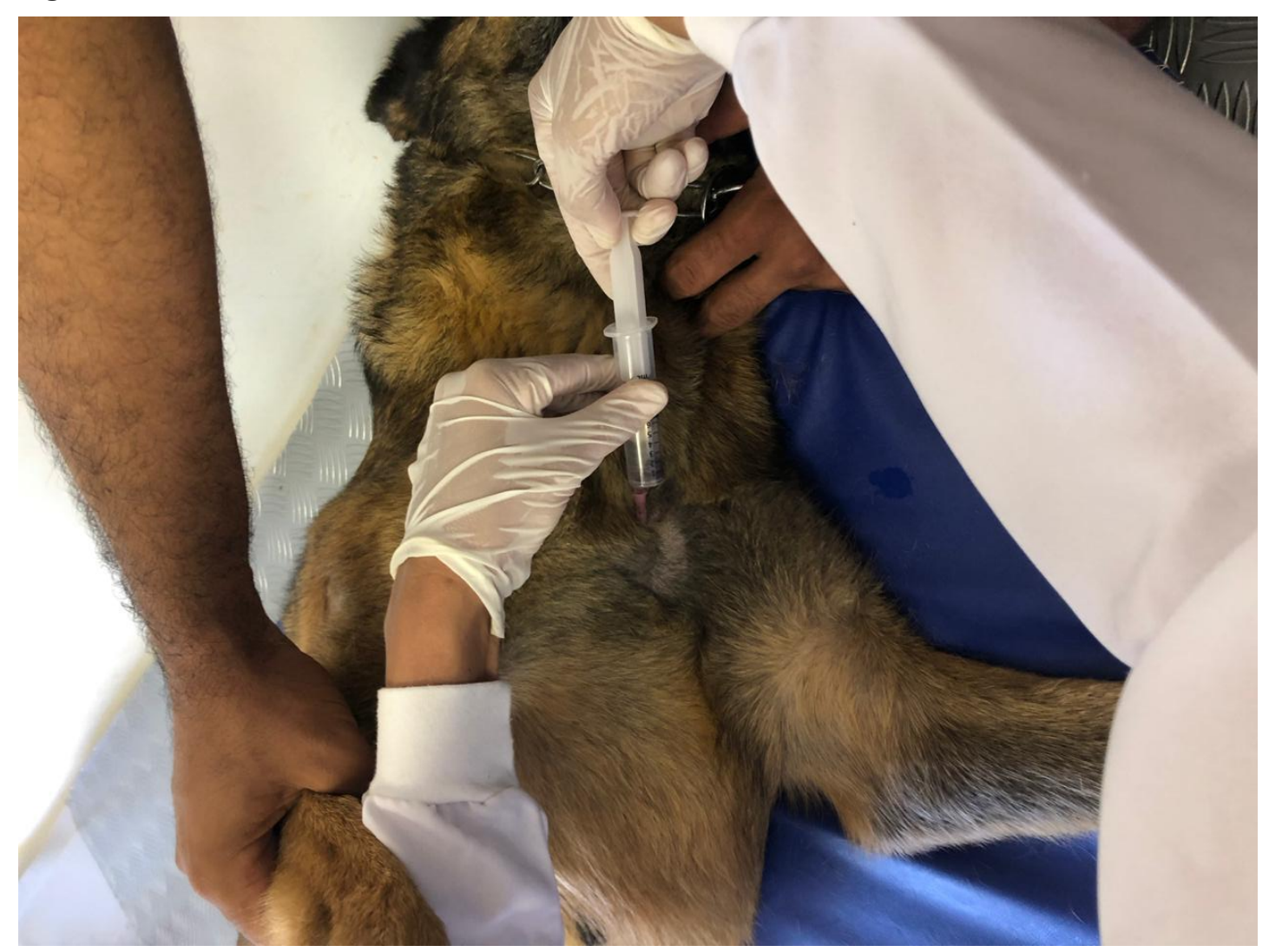

Fonte: Donato, 2019 
Para a coleta da amostra de medula óssea (Figura 1) os cães foram sedados, utilizando cloridrato de quetamina $(10 \mathrm{mg} / \mathrm{kg})$ associado à acepromazina $(0,2 \mathrm{mg} / \mathrm{kg})$ por via intramuscular. Foi realizada a tricotomia, higienização com água e sabão e antissepsia com álcool 70\% e álcool iodado no manúbrio esternal. Foi introduzido uma agulha 1,2 x 40 mm e seringa de $20 \mathrm{~mL}$ e aspirado o material medular. O material aspirado foi adicionado em tubo com EDTA (Becton Dickinson - BD, Nova Jersey, EUA) para a realização da qPCR na Fundação Oswaldo Cruz (Fiocruz), Curitiba.

A coleta de sangue foi realizada em todos os cães do estudo, por meio de venopunção da veia safena, cefálica ou femoral, onde foram coletados e armazenados $1 \mathrm{~mL}$ de sangue em tubos sem anticoagulante e a realização dos ensaios ALERE $^{\circledR}$ e DPP $^{\circledR}$ LVC (BioManguinhos ${ }^{\circledR} /$ FIOCRUZ, Brasil). $O$ teste ELISA (EIE LVC/ Bio-manguinhos ${ }^{\circledR}$ ) foi adotado em animais positivos aos testes de triagem.

No final dos dois períodos de coleta, as amostras de medula óssea, sangue e foram encaminhadas ao LABOCIEN- Uniceub, Brasília, onde foram processadas (Figura 3), identificadas (Figura 2) e armazenadas em freezers na temperatura de -18 o C (Figura 1 ) antes de serem encaminhados ao IOC-Fiocruz.

Figura 2 - Freezer Labocien -18 C com amostras processadas, lado direito mostrando a parte interna e lado esquerdo parte externa.

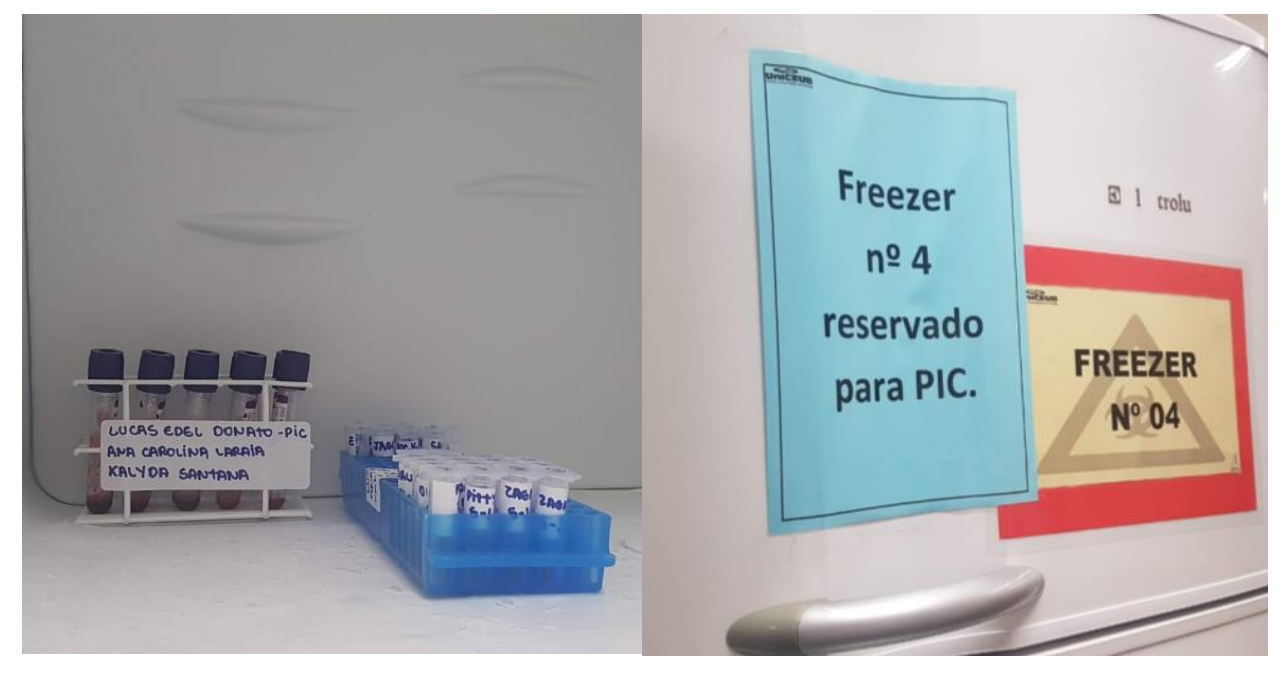

Fonte: Ciarlini, 2019 
Figura 3 - Preparação para o processamento das amostras na centrífuga.

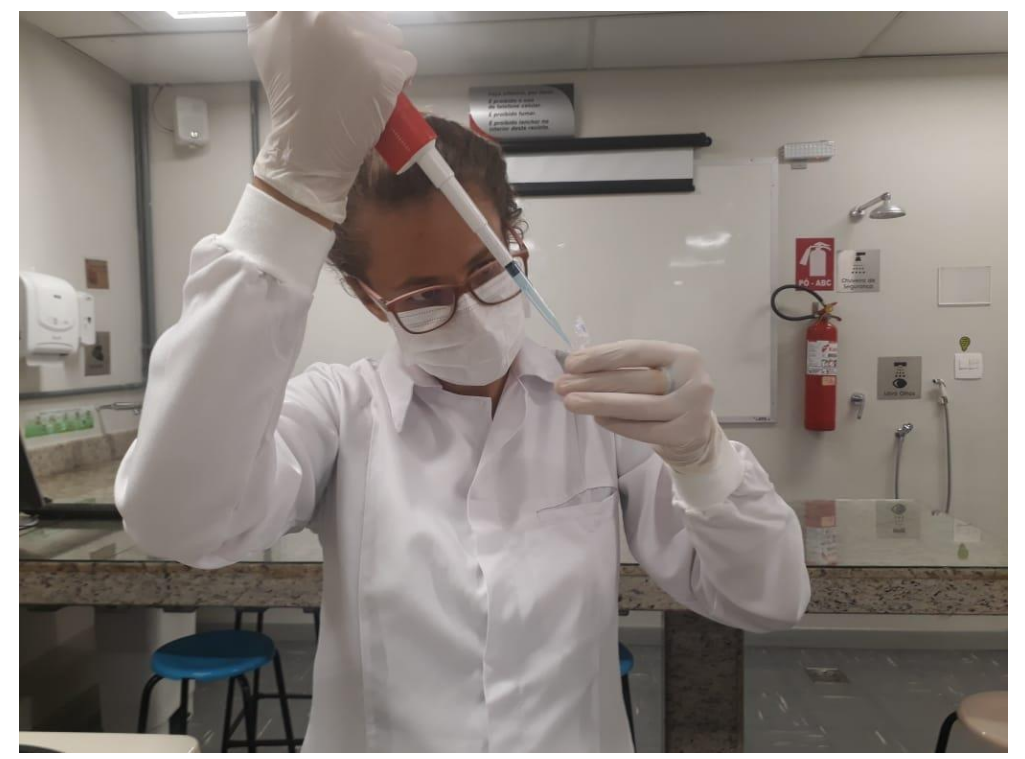

Fonte: Ciarlini, 2019

Figura 4 - Identificação das amostras

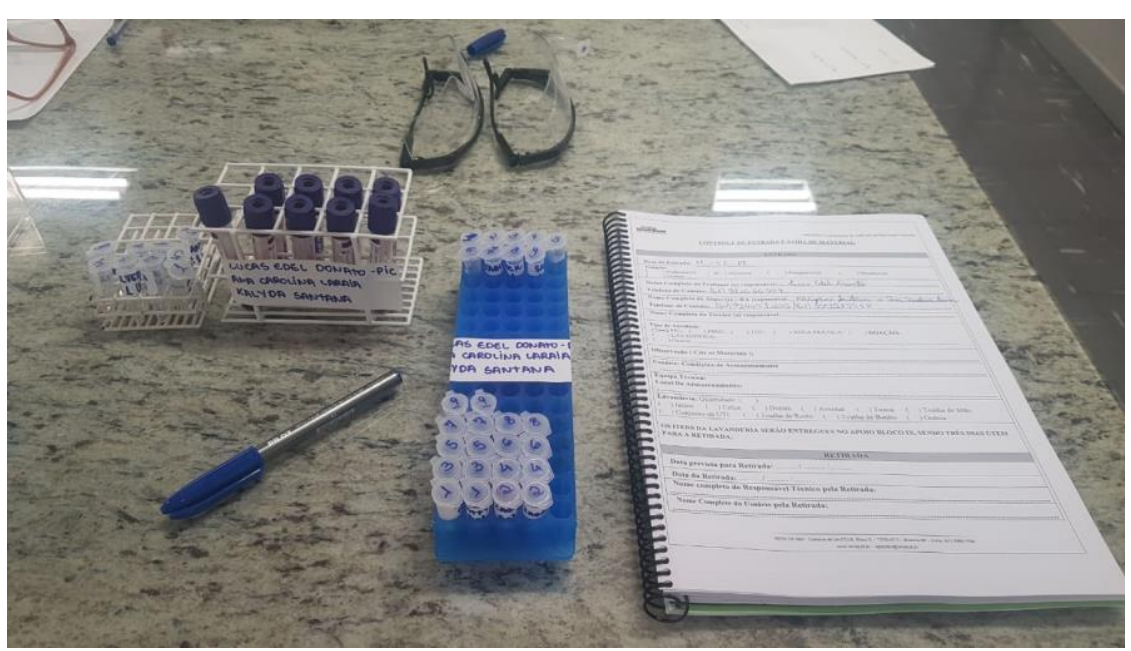

Fonte: Ciarlini, 2019

\subsection{Exame sorológico DUAL PATH PLATFORM - DPP ${ }^{\circledR}$ LVC.}

O teste DPP ${ }^{\circledR}$ LVC detecta anticorpos anti-Leishmania através do uso da proteína K39 (rK39) como antígeno. Esta proteína é obtida por meio do gene clonado a partir do L. infantum e que possui uma repetição de 39 aminoácidos presente entre as espécies de leishmania (L. donovani, L. infantum). A detecção de anticorpos anti-Rk39 indica infecção.

Este teste rápido foi utilizado em todos os animais do estudo para o diagnóstico no tempo 0 e como controle de soroconversão e infecção após as vacinações no tempo 1 (Figura 
5). Conforme as orientações do fabricante, foi utilizado um volume aproximado de $5 \mu \mathrm{L}$ de sangue total sem anticoagulante seguidas de 2 gotas do tampão no poço 1 (amostra + tampão). Após 5 minutos, foram adicionados 4 gotas do tampão no poço 2 (tampão), respeitando de 10 a 15 minutos para a leitura dos resultados.

Figura 5 - Momento de execução do teste DPP ${ }^{\circledR}$ LVC

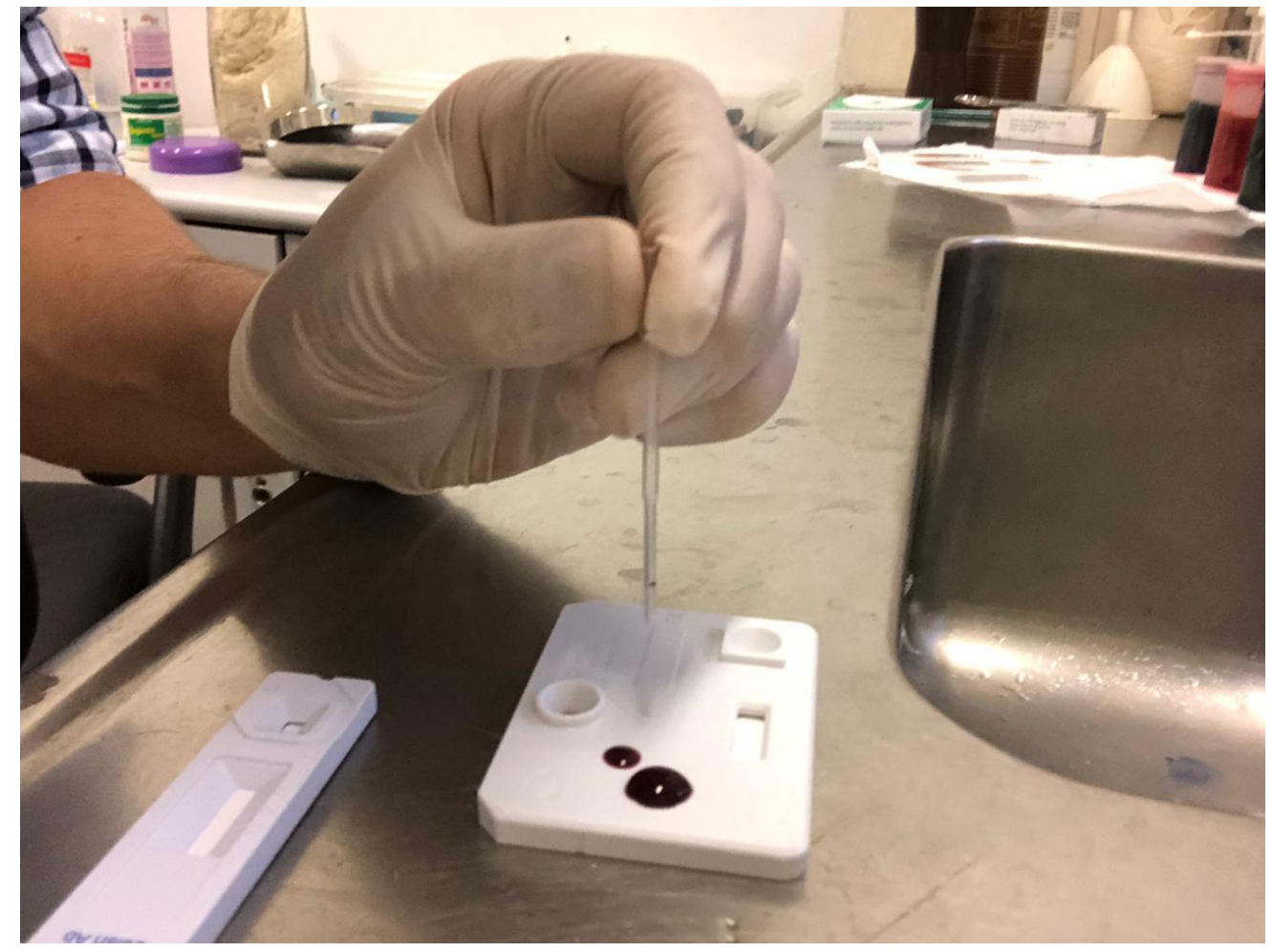

Fonte: Donato, 2019.

O teste foi considerado positivo quando as duas faixas (amostra e controle) estiveram visíveis (Figura 6).

Figura 6. Dual Path Platform - DPP LVC, teste imunocromatográfico para leishmaniose visceral canina. Ao lado esquerdo, um teste positivo com as duas faixas visíveis (faixa vermelha). Ao lado direito, um teste negativo com apenas a faixa controle visível. 


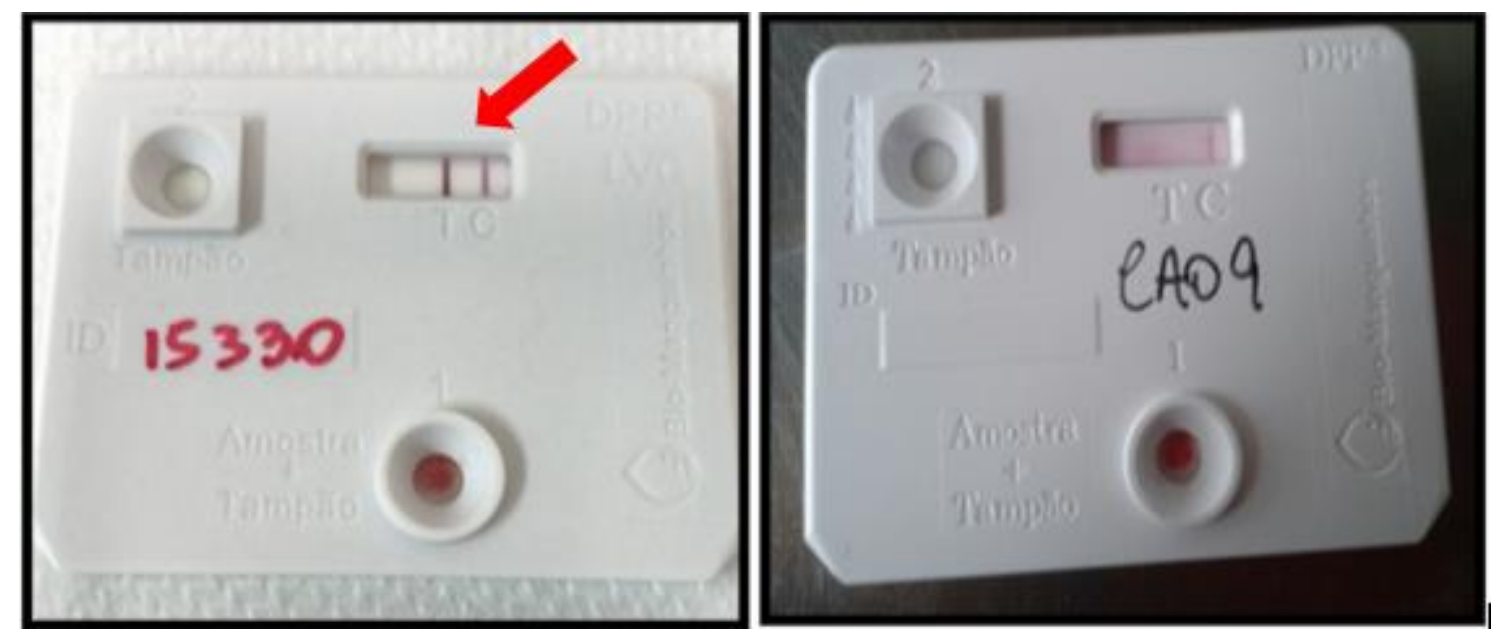

Fonte: Lapclin - Dermzoo.

\subsection{Exame sorológico ALERE ${ }^{\circledR}$ LEISHMANIOSE AC TEST KIT.}

O teste sorológico Alere é um imunoensaio imunocromatográfico para detecção qualitativa de anticorpos anti Leishmania infantum (antígenos rK9, rK39 e rK26) em amostras de soro, plasma e sangue total canino, com resultados qualitativos (positivo [Figura 5] ou negativo), para o diagnóstico in-vitro.

Alere Leishmaniose Ac Test Kit possui uma letra T (como linha teste) e uma linha C (como linha controle) na superfície do cassete. Ambas as linhas não são visíveis na janela de resultado antes da aplicação da amostra. A linha de controle (C) é usada para controle do procedimento do teste estiver correto e se os reagentes da linha aparecer se o procedimento do teste estiver corretos se os reagentes da linha de controle estiverem funcionando. Uma linha roxa será visível na janela de resultado $(T)$ se houver a presença de anticorpos anti Leishmania infantum.

Este teste rápido também foi utilizado em todos os animais do estudo para o diagnóstico no tempo 0 e como controle de soroconversão e infeç̧ão após as vacinações no tempo 1 (Figura 8). Conforme as orientações do fabricante, foi utilizado um volume aproximado de $10 \mu \mathrm{L}$ de sangue total sem anticoagulante seguidas de 2 gotas do tampão diluente no poço único (amostra+tampão). A interpretação dos resultados foram feitas após 20 minutos. 
Figura 7. $\operatorname{ALERE}^{\circledR}$ Leishmaniose $\mathrm{AC}$ Test Kit., teste imunocromatográfico para leishmaniose visceral canina. A imagem representa um teste positivo com as duas faixas visíveis (faixa vermelha).

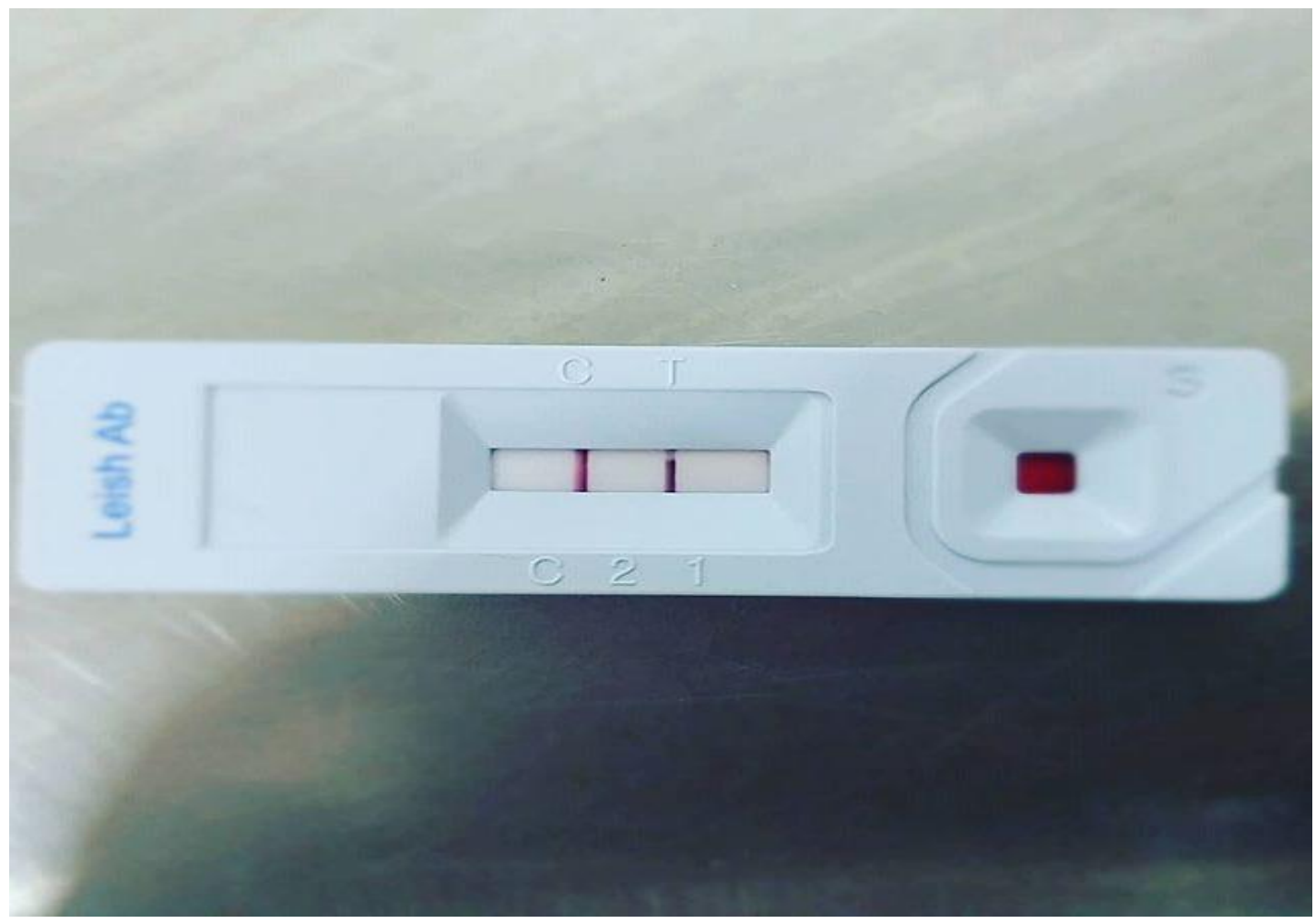

Fonte: Donato, 2019

Figura 8 - Pipetagem de amostra do estudo, na área tampão do teste $\operatorname{ALERE}^{\circledR}$

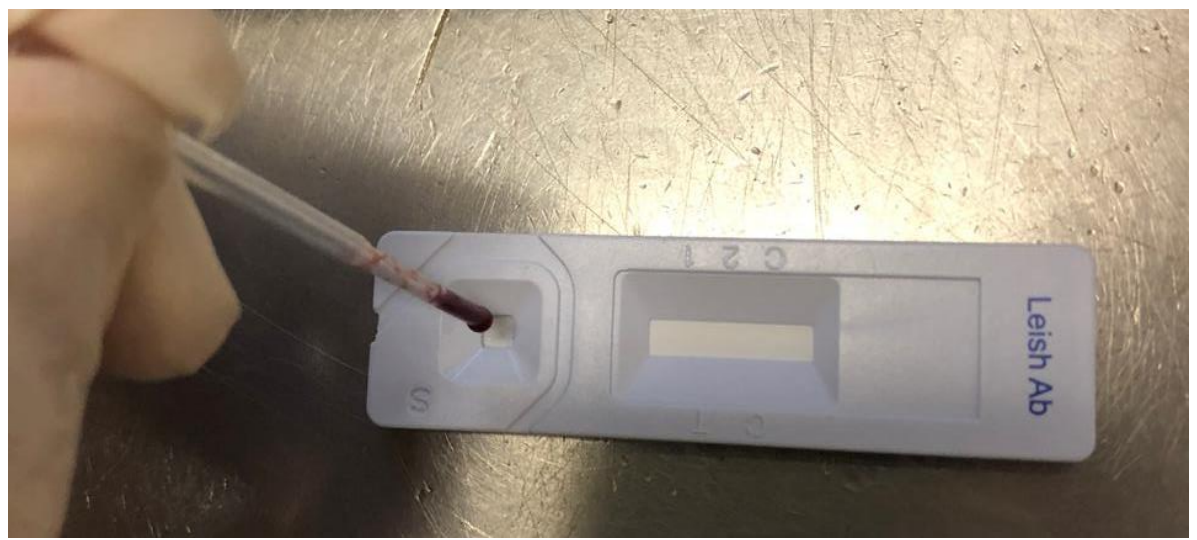

Fonte: Donato, 2019 


\subsection{Exame sorológico ELISA (EIE LVC Bio-manguinhos ${ }^{\circledR}$ )}

Os soros dos animais reagentes nos testes rápidos imunocromatográficos foram encaminhados a Diretoria de Vigilância em Zoonoses da Secretaria de Saúde do Governo do Distrito Federal para realizar a técnica do Ensaio Imunoenzimático (ELISA).

Colocou-se, na placa de ELISA, solução tampão contendo o primeiro anticorpo (Leishmania major like) com concentração conhecida e suficiente para adsorver nos "poços" ("wells") da placa. Os poços são lavados utilizando tampão, de forma a retirar o tampão, mas deixar o anticorpo aderido à placa. A próxima etapa foi de adicionar a amostra com os antígenos na placa e realiza uma nova lavagem e os antígenos que reagiram com o anticorpo aderido a placa permanecerá aderido, entretanto, os antígenos não ligados serão removidos. O processo continua com a incubação do segundo anticorpo e terceiro anticorpo (anti espécie), seguida de lavagem utilizando conjugado (enzima). Por fim é adicionado substrato para revelação. Este substrato incolor que, quando ativado pela porção enzimática do ligante, produz um produto final corado. A mudança de cor pode ser lida diretamente em aparelho apropriado. Em geral, bloqueia-se a reação para evitar que o produto final fique muito escuro e atrapalhe a leitura do teste. Além de bloquear a reação, é possível adicionar um ácido que provoque mudança para uma cor cuja absorbância é melhor detectada pelo leitor de ELISA.

\subsection{Exame molecular qPCR.}

O teste qPCR consiste em 4 etapas que foram realizadas no IOC - Fiocruz localizado em Curitiba-PR. A qPCR permite o monitoramento de sequências singulares de kDNA durante a reação e, por conta da presença de parasitos em latência na infecção por Leishmania, este teste quantitativo ajudou a monitorar a carga parasitária dos cães incluídos neste estudo e consequentemente o diagnóstico definitivo.

A primeira etapa consiste na extração (Figura 9) e purificação de DNA a partir das amostras de medula óssea .Para essa etapa foi utilizado o "kit" DNeasy ${ }^{\circledR}$ Blood \& Tissue (Qiagen ${ }^{\circledR}$ ), na plataforma semi automatizada de extração de ácidos nucleicos Qiacube (Qiagen ${ }^{\circledR}$ ) (Figura 10), seguindo as recomendações do fabricante. O DNA purificado foi identificado e estocado a -20 으. 
Figura 9 - Etapa de preparação para extração de DNA

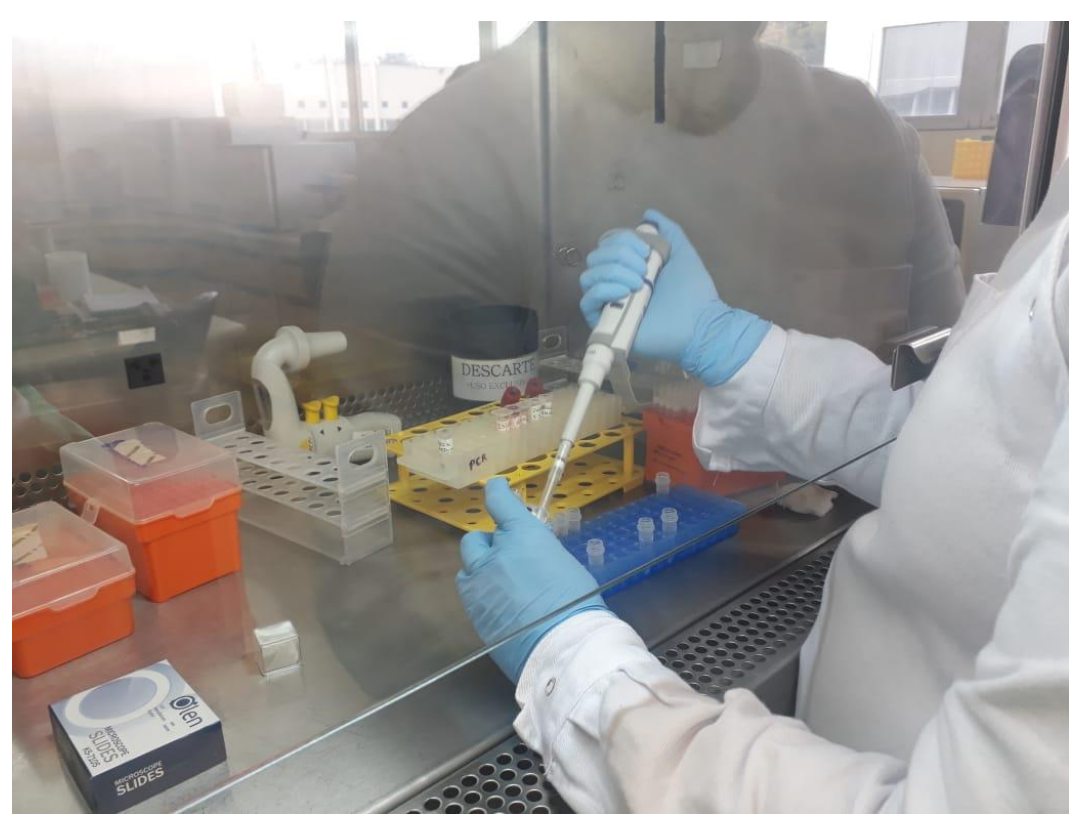

Fonte: Santana, 2019

A segunda etapa consiste na quantificação do DNA por fluorimetria. Esta técnica permitiu a quantificação de DNA utilizando corantes fluorescentes, que são detectados pela plataforma Qubit ${ }^{\circledR}$ 2.0 Fluorometer (Invitrogen ${ }^{\circledR}$ ) quando utilizado o "kit" Qubit ${ }^{\circledR}$ dsDNA HS Assay, seguindo as instruções do fabricante.

Figura 10 - Plataforma semi-automatizada de extração de ácidos nucleicos Qiacube (Qiagen ${ }^{\circledR}$ )

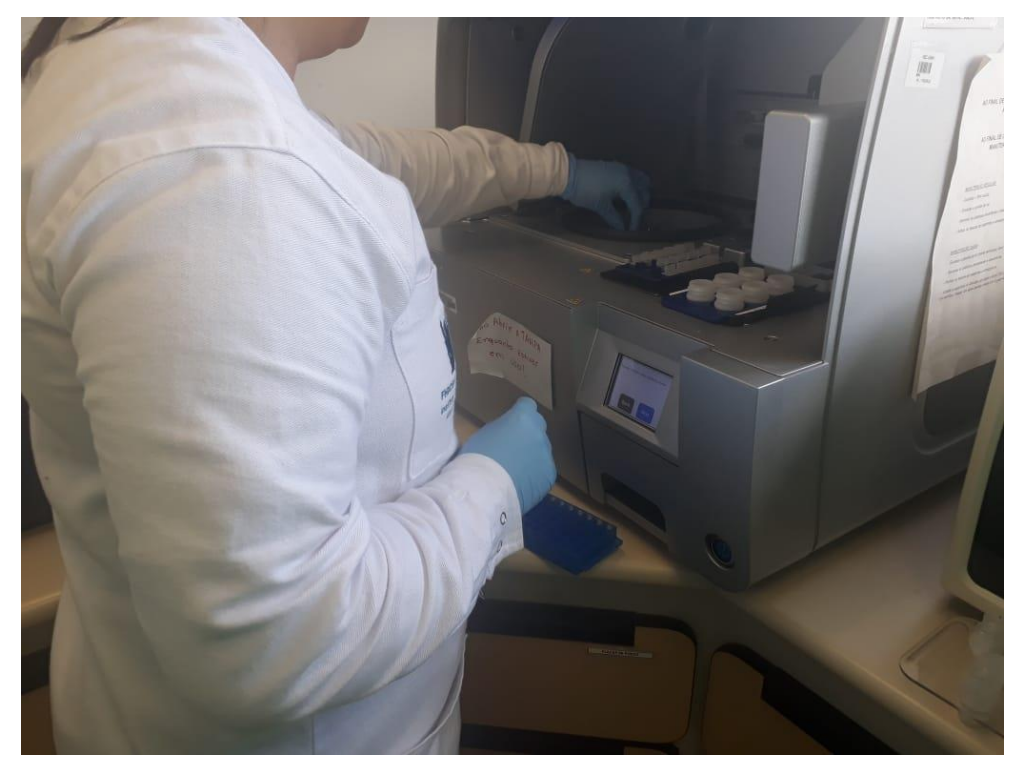

Fonte: Santana, 2019 
Para a quantificação, inicialmente foram estabelecidas curvas de concentração de DNA utilizando os dois padrões do "kit", sendo que um representou o menor ponto da curva (padrão 1) e o outro o maior (padrão 2). A solução de trabalho foi preparada em um microtubo, utilizando-se $199 \mu \mathrm{L}$ de tampão Qubit e $1 \mu \mathrm{L}$ de reagente Qubit para cada amostra. Para a preparação dos padrões da curva (padrão 1 e padrão 2) foram adicionados $190 \mu \mathrm{L}$ da solução de trabalho e $10 \mu \mathrm{L}$ do padrão 1 ou 2, respectivamente, sendo as preparações homogeneizadas e incubadas a temperatura ambiente por dois minutos. Para a quantificação das amostras, foram adicionados $199 \mu \mathrm{L}$ da solução de trabalho e $1 \mu \mathrm{L}$ da amostra de DNA que foram incubadas a temperatura ambiente por dois minutos. Após a leitura no fluorímetro, a concentração de DNA em nanogramas por microlitro $(\mathrm{ng} / \mu \mathrm{L})$ foi definida através da curvapadrão, sendo os valores registrados.

Após a extração, as amostras foram amplificadas utilizando sondas de hidrólise (sistema $\operatorname{TaqMan}^{\circledR}$ ) na plataforma StepOne ${ }^{\mathrm{TM}}$ (Applied Biosystems ${ }^{\circledR}$, by Thermo Fischer Scientific ${ }^{\circledR}$, MA, EUA). Cada amostra foi testada em triplicata.

A sonda de hidrólise (TaqMan ${ }^{\circledR}$ MGB) e o PCR foram desenhados visando as regiões conservadas do kDNA de L. infantum. Os iniciadores LEISH-1 (5'AACTTTTCTGGTCCTCCGGGTAG-3') e LEISH-2 (5'-ACCCCCAGTTTCCCGCC-3') e a sonda de hidrólise (FAM- 5'AAAAATGGGTGCAGAAAT- 3'- NFQ -MGB) utilizados foram descritos anteriormente no protocolo de Francino e colaboradores (2006).

O volume final da reação foi de $25 \mu \mathrm{L}, 5 \mu \mathrm{L}$ de amostra e $20 \mu \mathrm{L}$ de mix contendo 12,5 $\mu \mathrm{L}$ de Universal Mastermix (Applied Biosystems ${ }^{\circledR}$, by Thermo Fischer Scientific ${ }^{\circledR}$, MA, EUA), 1,5 $\mu \mathrm{L}$ dos iniciadores LEISH-1 e LEISH-2 a $900 \mathrm{nM}$ e $2,5 \mu \mathrm{L}$ da sonda a $200 \mathrm{nM}$ e $2 \mu \mathrm{L}$ de água ultra pura.

O protocolo dos ciclos foi: 1 ciclo de $50^{\circ} \mathrm{C}$ por 2 minutos, 1 ciclo de $95^{\circ} \mathrm{C}$ por 10 minutos e 40 ciclos de $95^{\circ} \mathrm{C}$ por 15 segundos e de $60^{\circ} \mathrm{C}$ por 1 minuto.

A reação foi realizada em placa de 48 poços (Figura 11) (Applied Biosystems ${ }^{\circledR}$, by Thermo Fischer Scientific ${ }^{\circledR}, M A, E U A$ ) que foi vedada com filme adesivo (Applied Biosystems ${ }^{\circledR}$ , by Thermo Fischer Scientific ${ }^{\circledR}$, MA, EUA) após a pipetagem da reação. 
Figura 11 - Placa preta, com 48 poços na mão da pesquisadora.

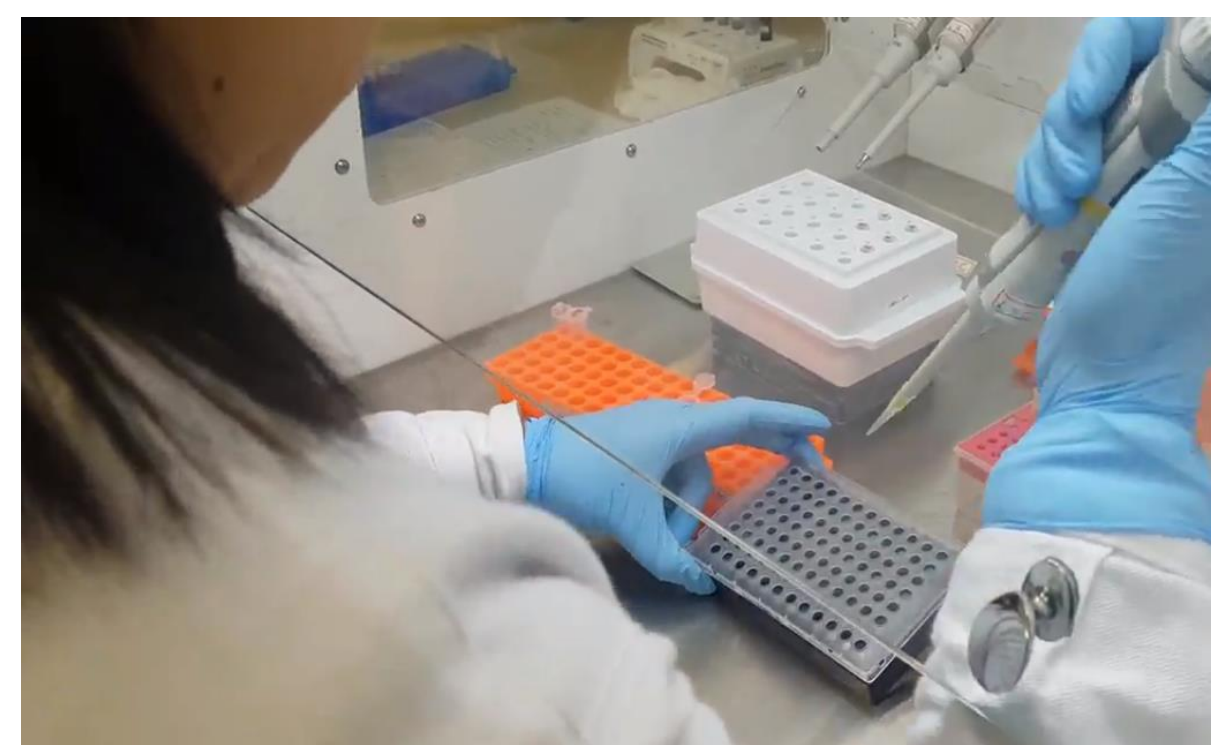

Fonte: Ciarlini, 2019

Para a quantificação, em cada placa foi utilizada uma curva padrão confeccionada com cultura de $L$. infantum representando os pontos de $2.500,250,25,2,5,0,25$ Equivalente genômico (gEq) de L. infantum/reação de qPCR (CAMPOS, et al. 2017).

Em cada amplificação foram usados controles positivos e negativos e o threshold determinado foi de 0,1 para todas as amostras, pela determinação do ponto em que a fluorescência emitida ultrapassou o limite considerado negativo. O limite para a obtenção dos resultados detectáveis foi fixado em 37 ciclos. As amostras que apresentaram sinal de fluorescência após o ciclo 37 foram consideradas indetectáveis.

A fim de identificar resultados falsos-negativos possivelmente causados pela presença de inibidores na reação ou de amostra de DNA degradado, um teste foi realizado em todas as amostras indetectáveis pela qPCR. Foi utilizado o ensaio Taqman $^{\circledR}$ Gene Expression Assay system (Applied Biosystems, Foster City, CA), que contém par de iniciadores e sonda pré definidos para a realização da qPCR para a amplificação de um segmento do gene constitutivo canino que codifica para a subunidade proteica $\beta$-actina (Cf03023880_g1), num volume final de reação de $25 \mu \mathrm{L}$, contendo $2 \mu \mathrm{L}$ de DNA e $23 \mu \mathrm{l}$ de mistura de reação composta de $12,5 \mu \mathrm{L}$ de Universal Mastermix, 1,25 $\mu \mathrm{L}$ da solução de iniciadores e sonda e 9,25 $\mu \mathrm{L}$ de água ultrapura. 
Nesta etapa o resultado é qualitativo, sendo considerado detectável ou indetectável. As amostras de DNA que apresentaram amplificação são consideradas positivas e, por isso contendo DNA íntegro, e livre de inibidores. 


\section{Resultados e discussão}

Neste estudo, a vacina Leish-Tec ${ }^{\circledast}$ foi testada em uma população heterogênea de cães. Vale ressaltar que não objetivou-se avaliar a eficácia da vacina, visto que um delineamento de estudo com a presença de um grupo controle e uma amostra mais robusta de animais aleatórios seriam necessários para uma abordagem significante da eficácia da vacina.

A monitorização dos 9 animais que participaram da pesquisa teve um intervalo de 3 meses após a primeira coleta de amostras; consequentemente, a amostra do estudo foi composta por 09 animais. Todos os cães selecionados (100\%) foram imunizados com a vacina Leish-Tec ${ }^{\circledR}$. A idade média foi de 2,8 anos (01 à 07 anos). A amostra tem maior porcentagem de cães macho, representando $55,6 \%$ dos animais. As fêmeas correspondem à $44,4 \%$. Todos os cães da pesquisa possuíam bom estado geral de saúde. Durante o acompanhamento após a imunização, nenhuma reação adversa à vacina foi relatada, este fato pode se dar pelo bom estado imunológico dos animais e/ou pelo motivo que animais serem de grande porte, considerando que animais de pequeno porte são os mais sensíveis aos efeitos adversos relatados da vacina. (TESTASICCA et al. 2014).

Quadro 1. Resultados dos testes sorológicos $D^{\circledR}{ }^{\circledR}$ e ALERE $^{\circledR}$ e do teste molecular qPCR no tempo 0.

\begin{tabular}{|c|c|c|c|c|}
\hline & Cães & & & Testes confirmatórios \\
\hline & & & estes : & \\
\hline & & DPP & Alere & ELISA \\
\hline & 1 & - & - & - \\
\hline 0 & 2 & - & - & - \\
\hline 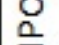 & 3 & + & + & - \\
\hline 咅 & 4 & - & - & - \\
\hline & 5 & {$[+]$} & - & - \\
\hline & 6 & - & - & - \\
\hline & 7 & - & - & - \\
\hline & 8 & - & - & - \\
\hline & 9 & - & - & - \\
\hline
\end{tabular}

Animais positivos (+); Animais negativos (-); Animais fraco positivo ([+]). 
No Tempo 0 (zero) da pesquisa, todos os cães vacinados apresentaram resultados negativos para LVC no teste Alere ${ }^{\circledR}$. No teste DPP ${ }^{\circledR} 2$ (dois) cães apresentaram resultado reagente, sendo eles representados pela amostra 3 (três) e a amostra 5 (cinco). Particularmente, a amostra 5 (cinco) apresentou resultado fraco positivo (Quadro 1). Cabe destacar que todos os cães incluídos no estudo apresentaram resultado negativo no qPCR de medula óssea (Figura 3)

No Tempo 1 (um), a amostra 3 (três), apresentou resultado reagente no teste Alere $^{\circledR} \mathrm{e}$ o restante das amostras apresentou resultado não reagente para o mesmo teste. No teste DPP $^{\circledR}$ seis cães apresentaram o resultado não reagente e três amostras apresentaram o resultado reagente; sendo elas representadas pelas amostras 2 (dois), 3 (três) e 9 (nove). Para as amostras reagentes ao teste DPP $^{\circledR}$, foram realizados o teste confirmatório ELISA ${ }^{\circledR}$, as amostras 2 (dois) e 9 (nove) apresentarem resultado negativo e a amostra 3 (três) apresentou resultado inconclusivo, a qual foi novamente testada expressando o resultado negativo (Quadro 2). Ademais todos estes cães foram negativos no tempo 1 (um), no exame qPCR (Figura 12) utilizando amostra de medula óssea.

Quadro 2. Resultados dos testes sorológicos DPP, ALERE e ELISA e do teste molecular qPCR no tempo 1.

\begin{tabular}{|c|c|c|c|c|c|}
\hline & Cães & & & & matórios \\
\hline & & & s sorol & & Testes moleculares \\
\hline & & DPP & Alere & ELISA & qPCR \\
\hline & 1 & - & - & - & - \\
\hline$\rightarrow$ & 2 & + & - & - & - \\
\hline$\stackrel{0}{2}$ & 3 & + & + & - & - \\
\hline छ & 4 & - & - & - & - \\
\hline & 5 & - & - & - & - \\
\hline & 6 & - & - & - & - \\
\hline & 7 & - & - & - & - \\
\hline & 8 & - & - & - & - \\
\hline & 9 & + & - & - & - \\
\hline
\end{tabular}

Animais positivos (+); Animais negativos (-).

O teste sorológico DPP ${ }^{\circledR}$ e Alere ${ }^{\circledR}$ não necessitam de equipamentos e são rapidamente executados, sendo imprescindíveis na detecção oportuna de animais infectados e na velocidade da implementação de medidas de controle. Entretanto, quando indicam resultados reagentes, deve ser realizado o teste confirmatório ELISA ${ }^{\circledR}$, onde todas as amostras 
do estudo se apresentaram não reagentes. Complementarmente, o teste qPCR também exprimiu resultados negativos. Dessa forma, as amostras 2 (dois) e 9 (nove) apontaram soroconverter ao teste $\mathrm{DPP}^{\circledR}$, por possuírem resultados negativos aos testes sorológicos no tempo 0 e ao teste confirmatório. Ainda que a vacina Leish-Tec ${ }^{\circledR}$ dispõe de antígenos ou DNA purificados distintos daquelas que constituem o teste DPP ${ }^{\circledR}$, por conta de suas limitações, falsos-positivos podem ser observados devido a resposta cruzada com outros tripanosomatídeos patogênicos e outros hemoparasitas (Toxoplasma gondii, Ehrlichia canis, Babesia canis, Neospora caninum e Anaplasma spp.) (CAMPOS, 2017; RIBEIRO et al., 2019; HARRUS et al., 2002; LEAL. 2009; LOPES et al., 2011; SILVA et al., 2011; LUCIANO et al., 2016). Como o teste Alere ${ }^{\circledR}$ possui a mesma proteína (rK28) que o teste DPP ${ }^{\circledR}$, a suposta soroconversão da amostra 3 (três) pode ser explicada pelo mesmo motivo.

Figura 12 - Resultado negativo no exame Qpcr, para todas as amostras no estudo.

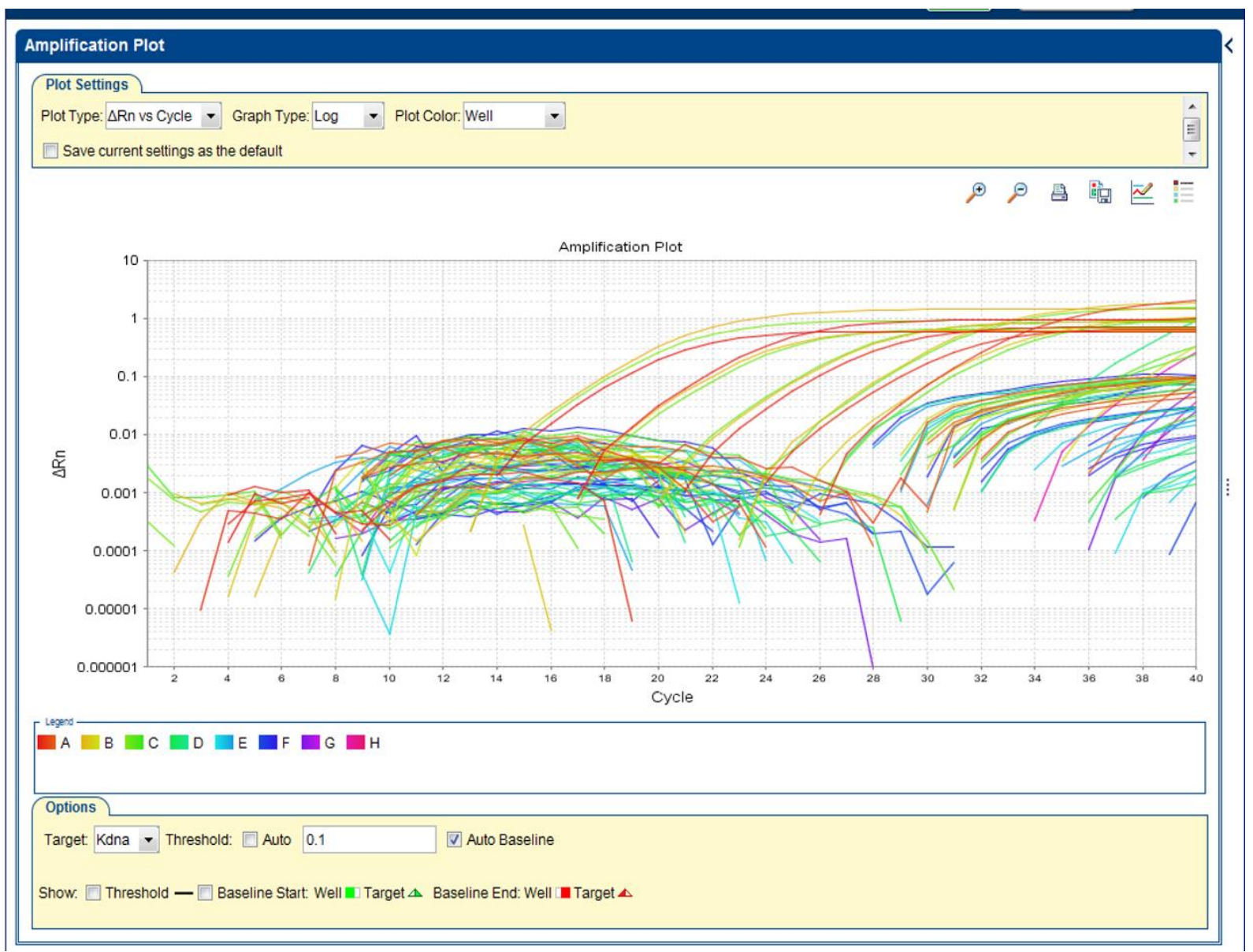

Fonte: Campos, 2019. 


\section{Considerações finais}

A avaliação sorológica dos animais pelos testes DPP-LVC, Alere e qPCR, foi executada com sucesso e os resultados corroboram os estudos realizados anteriormente e evidenciam que o protocolo adotado pelo Ministério da Saúde é seguro na detecção de animais infectados com Leishmaniose, visto que as amostras positivas para os testes de triagem (DPP) são testadas pelo teste confirmatório ELISA, proporcionando um método capaz de separar os animais realmente positivos daqueles imunizados. Entretanto, a análise documental mostrou, que há indícios da soroconversão de animais testados pelo DPP. Porém não há como generalizar os resultados, uma vez que este estudo não foi abrangente. Sugere-se um estudo com uma população maior em área endêmica para confirmação de tais resultados. 


\section{REFERÊNCIAS}

BANETH, G. SOLANO-GALLEGO, L. Leishmanioses. In: GREENE, C. E. Doenças

infecciosas em Cães e Gatos. 4. ed. Rio de Janeiro: Guanabara Koogan, 2015. cap.

73.

BENASSI, J. C. et al. Detection of Leishmania infantum DNA in conjunctival swabs of cats by quantitative real-time PCR. Experimental Parasitology, v. 177, p. 93-97, 2017. Disponível em: < https://www.ncbi.nlm.nih.gov/pubmed/28438522> Acesso em: 13 ago. 2019

BRASIL. Ministério da Agricultura, Pecuária e Abastecimento. Instrução Normativa Interministerial 31/2007. 9 de julho de 2007. Regulamento técnico para pesquisa, desenvolvimento, produção, avaliação, registro e renovação de licenças, comercialização e uso de vacina contra a leishmaniose visceral canina. Ministério da Saúde. Brasília, 2007.

BRASIL. Ministério da Saúde. Nota técnica conjunta no 01/2011-CGDT/ DEVIT/SUS/MS: esclarecimento sobre a substituição do protocolo diagnóstico da leishmaniose visceral canina (LVC) [online]. Secretaria de Vigilância em Saúde. Brasília, dez/2011.

CAMPOS, M. P. et al. Can vaccines against canine visceral leishmaniasis interfere with the serological diagnostics recommended by the Brazilian Ministry of Health?. Ciência Rural, v. 47, $\mathrm{n}$. 4, 2017. Disponível em: http://www.scielo.br/scielo.php?script=sci_arttext\&pid=S0103-84782017000400503> Acesso em: 13 ago. 2019.

COELHO E.A, et al. Immune responses induced by the Leishmania (Leishmania) donovani A2 antigen, but not by the LACK antigen, are protective against experimental Leishmania (Leishmania) amazonensis infection. Infection and Immunity. vol. 71, n. 7, p. 3988-3994, 2003. Disponível em: <https://www.ncbi.nlm.nih.gov/pubmed/12819086> Acesso em: 13 ago. 2019.

COSTA, L. N. G. Aplicação da técnica de PCR para o diagnóstico e monitoramento da leishmaniose tegumentar e visceral na região de Campinas-SP e Teresina-PI. 2014. $92 \mathrm{f}$. Dissertação (mestrado) - Universidade Estadual de Campinas, Faculdade de Ciências Médicas, Campinas, SP. Disponível em: <http://www.repositorio.unicamp.br/handle/REPOSIP/308553>. Acesso em: 13 ago. 2019.

COURA, J.R. Síntese das doenças infecciosas e parasitarias. Rio de Janeiro: Guanabara Koogan, 2009.

COURA, J.R. Dinâmica das Doenças Infecciosas e Parasitárias, 2. ed. Rio de Janeiro: Guanabara Koogan, 2013.

FERNANDES A. P., et al. Protective immunity against challenge with Leishmania (Leishmania chagasi) in beagle dogs vaccinated with recombinant A2 protein. Vaccine. v. 26, n. 46, p. 5888-5895, 2008. Disponível em: <https://www.ncbi.nlm.nih.gov/pubmed/18786587> Acesso em: 13 ago. 2019. 
FERNANDES, M. A. et al. Molecular detection of Leishmania infantum DNA according to clinical stages of leishmaniasis in dog. Revista Brasileira de Parasitologia Veterinária, v. 28, n. 2, p. 194-202, 2019. Disponível

em: http://www.scielo.br/scielo.php?script=sci_arttext\&pid=S1984-29612019000200194> Acesso em: 13 ago. 2019.

FIGUEIREDO, F. B. Validation of the Dual-path Platform chromatographic immunoassay (DPP ${ }^{\circledR}$ CVL rapid test) for the serodiagnosis of canine visceral leishmaniasis. Mem Inst Oswaldo Cruz, v. 113, n. 11, p. 1-7. 2018. Disponível em: < http://www.scielo.br/pdf/mioc/v113n11/16788060-mioc-113-11-e180260.pdf> Acesso em 13 ago. 2019.

FRANCINO, O. et al. Advantages of real-time PCR assay for diagnosis and monitoring of canine leishmaniosis. Veterinary Parasitology, v. 137, n. 3-4, p. 214-221, 30 abr. 2006. Disponível em: <https://www.sciencedirect.com/science/article/pii/S0304401706000288>. Acesso em: 14 ago. 2019.

$\mathrm{GHOSH}, \mathrm{A}$. et al. Immunization with $\mathrm{A} 2$ protein results in a mixed Th1/Th2 and a humoral response which protects mice against Leishmania donovani infections. Vaccine. v. 20. n. 1-2. pag. 56-66, 2002. Disponível em: <https://www.ncbi.nlm.nih.gov/pubmed/11567746> Acesso em: 13. ago. 2019.

GHOSH, A. et al. Protection against Leishmania donovani infection by DNA vaccination: increased DNA vaccination efficiency through inhibiting the cellular p53 response. Vaccine. v. 19. n. 23-24. pag. 3169-3178. 2001. Disponível em: <https://www.ncbi.nlm.nih.gov/pubmed/11312013> Acesso em: 13 ago. 2019.

GRAMICCIA, M. Recent advances in leishmaniosis in pet animals: epidemiology, diagnostics and anti-vectorial prophylaxis. Veterinary Parasitology. v. 181. pag. 23-30, 2011. Disponível em: < https://www.ncbi.nlm.nih.gov/pubmed/21570192> Acesso em: 13 ago. 2019.

GRIMALDI, G. JR., et al. Evaluation of a novel chromatographic immunoassay based on DualPath Platform technology (DPPR CVL rapid test) for the serodiagnosis of canine visceral leishmaniasis. Transactions of the Royal Society of Tropical Medicine and Hygiene. v. $106 \mathrm{n}$. 01. pag. 54-59, 2011. Disponível em: <https://www.ncbi.nlm.nih.gov/pubmed/22137538> Acesso em: 13 ago. 2019.

HARRUS, S. et al. Comparison of three enzyme-linked immunosorbant assays with the indirect immunofluorescent antibody test for the diagnosis of canine infection with Ehrlichia canis.

Veterinary Microbiology, v. 86, n. 4, p. 361-368, 2002. Disponível em: < https://www.ncbi.nlm.nih.gov/pubmed/11955786> Acesso em: 13 ago. 2019.

IBRAIM, I. C. Lipofosfoglicanos (LPGs) de Leishmania braziliensis e Leishmania infantum na ativação de macrófagos murinos e vias de sinalização celular. 2012. 74f. Dissertação (Mestrado) - Fundação Oswaldo Cruz, Centro de Pesquisas Rene Rachou, Belo Horizonte. Disponível em: <https://www.arca.fiocruz.br/handle/icict/6194>. Acesso em: 13 ago. 2019.

LEAL, C. R. B. Métodos disponíveis e possíveis para o diagnóstico da leishmaniose visceral americana canina. Bepa. v. 6, n. 69, p. 14-18, 2009. Disponível em: 
$<$ http://periodicos.ses.sp.bvs.br/scielo.php?script=sci_arttext\&pid=S1806$42722009000900002 \&$ lng=pt\&nrm=iso.> Acesso em: 13 ago. 2019.

LOPES, M. G. et al. Presence of antibodies against Toxoplasma gondii, Neospora caninum and Leishmania infantum in dogs from Piauí. Revista Brasileira de Parasitologia Veterinária, v. 20, n. 2, p. 111-114, 2011. Disponível em: < http://www.scielo.br/scielo.php?script=sci_arttext\&pid=S1984-29612011000200004> Acesso em: 13 ago. 2019

LUCIANO, R. M. et al. Cross reaction evaluation of Leishmania spp and Trypanosoma cruzi antigens in dogs' serologic response by indirect immunofluorescence test (IIF). Brazilian Journal of Veterinary Research and Animal Science, v. 46, n. 3, p. 181, 2016. Disponível em: < http://www.revistas.usp.br/bjvras/article/view/26765> Acesso em: 13 ago. 2019.

MINISTÉRIO DA AGRICULTURA, PECUARIA E ABASTECIMENTO (MAPA). Nota técnica - MAPA $n^{\circ}$ 038/2014/DFIP/DAS - suspensão da licença de fabricação e comercialização do produto Leishimune vacina contra leishmanioses visceral canina. Secretária de Defesa Agropecuária. Brasília, 2014.

MIZBANI A., et al. Recombinant Leishmania tarentolae expressing the A2 virulence gene as a novel candidate vaccine against visceral leishmaniasis. Vaccine. v. 28, n. 1, p. 53-62, 2010. Disponível em: <https://www.ncbi.nlm.nih.gov/pubmed/19818721> Acesso em: 13. 2019.

MORAES, SL. Diagnóstico laboratorial das principais doenças infecciosas e autoimunes. 3 ed. Rio de Janeiro : Guanabara Koogan, 2013.

MOREIRA, N. B. et al. Leishmaniose visceral canina: aspectos dermatológicos e dermatoses associadas. Acta Scientiae Veterinariae, [S.I.], v. 44, p. 01-04, feb. 2016. Disponível em: <http://revistas.bvs-vet.org.br/actascivet/article/view/31471>. Acesso em: 13 ago. 2019

OLIVEIRA, G. M. F. Leishmaniose Visceral Canina: relato de caso alóctone em Curitiba - PR. 2015. Monografia (Pós-Graduação, Especialização em Clínica Médica e Cirúrgica de Pequenos Animais) - Centro Estudos Superiores de Maceió, Fundação Educacional Jayme de Altavila. Curitiba, Paraná.

REGINA-SILVA, S. et al. Field randomized trial to evaluate the efficacy of the Leish-Tec ${ }^{\circledR}$ vaccine against canine visceral leishmaniasis in an endemic area of Brazil. Vaccine, v. 34, n. 19, p. 2233-2239, abr. 2016. Disponível em: < https://www.ncbi.nlm.nih.gov/pubmed/26997002> Acesso em: 13 ago. 2019.

RESENDE D. M., et al. Epitope mapping and protective immunity elicited by adenovirus expressing the Leishmania amastigote specific A2 antigen: correlation with IFN-gamma and cytolytic activity by CD8+ T cells. Vaccine. v. 26, n. 35, p. 4585-4593, 2008. Disponível em: < https://www.ncbi.nlm.nih.gov/pubmed/18588933> Acesso em: 13 ago. 2019.

RIBEIRO, C. R. et al. Prevalência da Leishmaniose Visceral Canina e coinfecções em região periurbana no Distrito Federal - Brasil. Ciência Animal Brasileira, v. 20, n. 0, 20 maio 2019. 
Disponível em: <http://www.scielo.br/scielo.php?script=sci_arttext\&pid=S180968912019000100309>. Acesso em: 13 ago. 2019.

SARIDOMICHELAKIS, M.N. Advances in the pathogenesis of canine leishmaniosis: epidemiologic and diagnostic implications. Veterinary Dermatology, v. 20, ed. 5-6, p. 471-489, out. 2009. Disponível em: <https://onlinelibrary.wiley.com/doi/abs/10.1111/j.13653164.2009.00823.x>. Acesso em: 13 ago 2019.

SILVA, D. A. et al. Geographical Expansion of Canine Visceral Leishmaniasis in Rio De Janeiro State, Brazil. Revista do Instituto de Medicina Tropical de São Paulo, v. 57, p. 435-438, 2015. Disponível em: <http://www.scielo.br/scielo.php?script=sci_arttext\&pid=S003646652015000500435> Acesso em: 13 ago. 2019.

SILVA, D. A. et al. Laboratory tests performed on Leishmania seroreactive dogs euthanized by the leishmaniasis control program. Veterinary Parasitology, v. 179, n. 1-3, p. 257-261, 2011. Disponível em: <https://www.ncbi.nlm.nih.gov/pubmed/21349644> Acesso em: 13 ago. 2019.

SUNDAR, S. Leishmaniose. In: KASPER, D. L. Doenças infecciosas de Harrison. 2. ed. Porto Alegre: AMGH, 2015. cap. 12.

TAYLOR, M.A.; COOP, R.L.; WALL, R.L. Parasitologia Veterinária. 3. ed. Rio de Janeiro: Guanabara Koogan, 2010.

TESTASICCA, M. C. de S. et al. Antibody responses induced by Leish-Tec ${ }^{\circledR}$, an A2-based vaccine for visceral leishmaniasis, in a heterogeneous canine population. Veterinary Parasitology, v. 204, n. 3-4, p. 169-176, 29 ago. 2014. Disponível em: <https://www.sciencedirect.com/science/article/pii/S0304401714002349?via\%3Dihub>.

Acesso em: 13 ago. 2019.

TRONCARELLI, M. Z., et al. Leishmania spp. and/or Trypanosoma cruzi diagnosis in dogs from endemic and nonendemic areas for canine visceral leishmaniasis. Veterinary Parasitology, v.164, n. 2-4, p. 118-123, 2009. Disponível em: <https://scihub.tw/https://www.ncbi.nlm.nih.gov/pubmed/19625128> Acesso em: 13 ago. 2019.

ZANIN, F. H. C. et al. Evaluation of immune responses and protection induced by A2 and nucleoside hydrolase (NH) DNA vaccines against Leishmania chagasi and Leishmania amazonensis experimental infections. Microbes and Infection, v. 9, n. 9, p. 1070-1077, jul. 2007. Disponível em: https://www.sciencedirect.com/science/article/pii/S1286457907001888> Acesso em: 13 ago. 2019. 